UDC 620.193:669.715

Author: LATYPOVA Dina Rinatovna, Lecturer of the Chair "Technology of Petroleum Devices», Ufa State Petroleum Technological University; Cosmonavtov str., 1, Ufa, Bashkortostan, The Russian Federation, 450062, E-mail: d.r.latypova@mail.ru;

Author: LATYPOV Oleg Renatovich, Doctor of Engineering, Professor Assistant, Professor of the Chair «Technology of Petroleum Devices», Ufa State Petroleum Technological University; Cosmonavtov str., 1, Ufa, Bashkortostan, The Russian Federation, 450062,

E-mail: o.r.latypov@mail.ru;

Author: BUGAI Dmitriy Efimovich, Doctor of Engineering, Professor, Professor of the Chair «Technology of Petroleum Devices», Ufa State Petroleum Technological University;

Cosmonavtov str., 1, Ufa, Bashkortostan, The Russian Federation, 450062

\title{
INFLUENCE OF ELECTRODE POTENTIAL ON THE DEPTH OF PITTING CORROSION IN THE SURFACE STRUCTURES OF PLACED STEEL
}

\section{Extended Abstract:}

The paper presents the results of the research that studied how the penetration depth of pitting corrosion in the surface structures of clad steel depends on the steel surface electrode potential. The tests were carried out on the stainless surface of the samples made from steel 09G2S/08X13, which is widely used in production of metal structures for the oil and gas industry due to its necessary mechanical properties and corrosion resistance. The operation process of this steel runs in the technological environment with high corrosivity. The influence of pitting components of the corrosive medium $\left(\mathrm{Cl}^{-} \mathrm{I} \mathrm{S}_{2} \mathrm{O}_{3}{ }^{2-}\right.$ ions) on the diffusion of oxidants and the development of local processes of destruction of a passive film is shown. It is noted that the maximum influence of the electrode potential on the development of pitting corrosion occurs in the area of secondary passivation. In this case, the depth of pitting can reach $180 \mu \mathrm{m}$. Further displacement of the electrode potential of the surface contributes to the phenomenon of transmissivity and leads to the appearance of significant mechanical stresses in the surface structures, causing their cracking. Investigation of surface structures will establish mechanisms for their destruction, and timely implement the necessary anticorrosion measures.

Key words: pitting depth, passive film, stainless steel, surface profile, electrode potential, polarization curves. 


\section{MACHINE-READABLE INFORMATION ON CC-LICENSES (HTML-CODE) IN METADATA OF THE PAPER}

$<$ a rel="license" href="http://creativecommons.org/licenses/by/4.0/"><img alt="Creative Commons License" style="borderwidth:0" src="https://i.creativecommons.org/l/by/4.0/88x31.png" $/></ \mathrm{a}><$ br $/><$ span xmlns:dct="http://purl.org/dc/ terms $/ "$ property $="$ dct:title" $>$ Influence of electrode potential on the depth of pitting corrosion in the surface structures of placed steel</span $>$ by $<$ a xmlns:cc="http://creativecommons.org/ns\#" href="Nanotehnologii v stroitel'stve =

Nanotechnologies in Construction. 2018, Vol. 10, no. 3, pp. 167-178. DOI: dx.doi.org/10.15828/2075-8545-2018-10-3-

167-178." property="cc:attributionName" rel="cc:attributionURL">Latypova D.R., Latypov O.R., Bugai D.E. $</ a>$ is

licensed under a $<$ a rel="license" href="http://creativecommons.org/licenses/by/4.0/" $>$ Creative Commons Attribution 4.0 International License $</ \mathrm{a}>$. $<\mathrm{br} />$ Based on a work at $<\mathrm{a}$ xmlns:dct="http://purl.org/dc/terms/" href="http://nanobuild.ru/ en_EN/nanobuild-3-2018/" rel="dct:source" $>$ http://nanobuild.ru/en_EN/nanobuild-3-2018/</a $>$. $<$ br $/>$ Permissions beyond the scope of this license may be available at $<$ a xmlns:cc="http://creativecommons.org/ns\#" href="d.r.latypova@mail.ru" rel=

"cc:morePermissions" $>$ d.r.latypova@mail.ru $</ a>$.

\section{References:}

1. Alcybeeva A.I., Burlov V.V., Kuzinova T.M., Sokolov V.L., Reshetnikov S.M. Pittingovaya korroziya stalej $\mathrm{v}$ usloviyah pervichnoj pererabotki nefti [Pitting corrosion of steels in the conditions of primary oil refining]. Korroziya: materialy, zashchita. [Corrosion: materials, protection]. 2009. № 3. pp. 6-10. (In Russian).

2. Dayrova K.N., Latypov O.R., Bugai D.E. Korroziya kolonny gidroochistki dizel'nogo topliva [Corrosion of diesel fuel hydrotreating column]. In mater. 67-j nauch.-tekhn. konf. studentov, aspirantov i molodyh uchenyh UGNTU [In Proc. 67 ${ }^{\text {th }}$ scientifictechnical. Conf. students, graduate students and young scientists of UGNTU]. 2016. Vol. 1. pp. 217-218. (In Russian).

3. Latypova D.R. Kontaktnaya korroziya plakirovannogo sloya atmosfernoj kolonny [Contact corrosion of a clad layer of an atmospheric column]. Sovremennye tekhnologii v obrazovanii i promyshlennosti: ot teorii k praktike. Sbornik mater. II Vnutrivuz. nauch.-prakt. konf. [ Modern technologies in education and industry: from theory to practice. Collection of materials II Intra-University. scientific-practical. conf.]. Ufa: Izd-vo «Neftegazovoe delo», 2018. pp. 165-167. (In Russian).

4. Kalimullina E.R., Latypova D.R., Bugai D.E. Zashchita holodil'nogo oborudovaniya ot lokal'noj korrozii [Protection of refrigeration equipment against local corrosion]. In mater. 69-j nauch.-tekhn. konf. studentov, aspirantov i molodyh uchenyh UGNTU. [In Proc. 69th scientific-technical. Conf. students, graduate students and young scientists of UGNTU]. 2018. Vol. 1. pp. 395. (In Russian).

5. Boev E.V., Afanasenko V.G., Latypov O.R., Cherepashkin S.E., Boeva N.I. Povyshenie kachestva vodotoplivnyh ehmul'sij [Improving the quality of water-fuel emulsions]. Ural'skij nauchnyj vestnik. [The Urals Scientific Herald]. 2018. Vol. 2, № 4. pp. 1922. (In Russian).

6. Mukanova S.S., Latypova D.R., Bugai D.E. Vliyanie temperatury na skorost' pittingovoj korrozii neftepererabatyvayushchego oborudovaniya, vypolnennogo iz nerzhaveyushchih stalej [Effect of temperature on the rate of pitting corrosion of oil 
refining equipment made of stainless steels]. In mater. 69-j nauch.-tekhn. konf. studentov, aspirantov i molodyh uchenyh UGNTU. [ Materials of the 69th scientifictechnical. Conf. students, graduate students and young scientists of UGNTU]. 2018. T. 1.pp. 409. (In Russian).

7. Latypov O.R. Reduction of Salt Deposits on the Surface of Oilfield Equipment by Management of Electrochemical Parameters of the Medium. Chemical and Petroleum Engineering. November 2015, Vol. 51, Issue 7. pp. 522-525. DOI: dx.doi.org/10.1007/ s10556-015-0079-z.

8. Shcherbakov A.I., Kasatkina I.V., Palicheva A.S., Zalavutdinov R.H., Dorofeeva V.N. Pittingovaya korroziya dupleksnoj stali 08H21N6M2T v nejtral'noj hloridnoj srede pri proizvodstve kalijnyh udobrenij [Pitting corrosion of duplex steel 08X21H6M2T in a neutral chloride environment in the production of potash fertilizers]. Korroziya: materialy, zashchita. [Corrosion: materials, protection]. 2017. № 9. pp. 31-36. (In Russian).

9. Ovchinnikova V.V., Latypova D.R., Latypov O.R., Bugai D.E. Shchelevaya korroziya neftezavodskogo oborudovaniya $\mathrm{v}$ usloviyah dejstviya ionov hlora [Slit corrosion of refinery equipment under the action of chloride ions]. In mater. 68-j nauch.-tekhn. konf. studentov, aspirantov i molodyh uchenyh UGNTU. [Materials of the 68th scientific-technical. Conf. students, graduate students and young scientists of UGNTU]. 2017. Kn. 1. p. 365. (In Russian).

10. Ovchinnikova V.V., Latypov O.R., Bugai D.E. Zashchita neftezavodskogo oborudovaniya ot shchelevoj korrozii v usloviyah dejstviya ionov hlora [Protection of refinery equipment against crevice corrosion under the action of chloride ions]. In mater. Vseross. nauch.-prakt. konf. s mezhdunar. uchastiem: Innovacionnye tekhnologii v promyshlennosti: obrazovanie, nauka i proizvodstvo. [Materials of the All-Russ. scientific-practical. Conf. with intern. participation: Innovative technologies in industry: education, science and production]. 2016. pp. 408-409. (In Russian).

11. Latypov O.R., Bugai D.E., Boev E.V. Method of Controlling Electrochemical Parameters of Oil Industry Processing Liquids. Chemical and Petroleum Engineering. July 2015, Vol. 51, Issue 3. pp. 283-285. DOI: dx.doi.org/10.1007/s10556-015-0038-8.

12. Latypov O.R., Bugai D.E., Ryabuhina V.N. Zashchita neftegazovogo oborudovaniya ot korrozii metodom polyarizacii [Protection of oil and gas equipment against corrosion by polarization]. Problemy sbora, podgotovki i transporta nefti i nefteproduktov. [Problems of collecting, preparing and transporting oil and oil products]. 2015. № 3 (101). pp. 155-164. (In Russian).

13. Latypova D.R., Malcev V.A., Latypov O.R., Laptev A.B., Bugai D.E. Ocenka kompleksnoj ingibitornoj zashchity ot korrozii vodooborotnyh sistem ustanovok gidrokrekinga [Evaluation of complex inhibitory corrosion protection of water rotation systems of hydrocracking units]. In mater. Mezhdunar. nauch.-prakt. konf.: Neftegazopererabotka - 2017. [In mater. Intern. scientific-practical. Conf.: Oil and gas processing - 2017]. 2017. pp. 208-209. (In Russian). 
14. Skuridin N.N., Latypova D.R., Pechenkina M.Yu., Latypov O.R., Bugai D.E., Ryabukhina V.N. Formirovanie protivokorrozionnyh plenok na metalle neftepromyslovogo oborudovaniya metodom polyarizacii tekhnologicheskih zhidkostej [Formation of anticorrosive films on the metal of oilfield equipment by the method of polarization of process liquids]. Neftyanoe hozyajstvo. [Oil industry]. 2018. № 5. pp. 84-86. DOI: 10.24887/0028-2448-2018-5-84-86 (In Russian).

15. Mirakyan S.M., Latypov O.R., Bugai D.E., Raskildina G.Z. Polyarizacionnye issledovaniya ingibiruyushchej ehffektivnosti nekotoryh vtorichnyh aminov [Polarization studies of the inhibitory efficacy of some secondary amines]. Bashkirskij himicheskij zhurnal [Bashkirsky Chemical Journal]. 2017. Vol. 24, № 2. pp. 42-45. (In Russian).

16. Cayetanu Zh.B., Latypova D.R., Latypov O.R. Issledovanie korrozii metalla obsadnyh trub [Investigation of corrosion of casing metal]. In mater. II Vnutrivuz. nauch.prakt. konf.: Sovremennye tekhnologii v obrazovanii i promyshlennosti: ot teorii k praktike [In Proc. of the II Intra-University. scientific-practical. Conf.: Modern technologies in education and industry: from theory to practice]. 2018. pp. 169-171. (In Russian).

17. Tyusenkov A.S. Chemical resistance of steel $13 \mathrm{CrV}$ (rus $13 \mathrm{X} \Phi \mathrm{A}$ ). Journal of Chemical Technology and Metallurgy. Vol. 52., Issue 4. 2017. pp. 766-772.

18. Ovchinnikova V.V., Pechenkina M.Yu., Latypov O.R. Vozmozhnost' formirovaniya produktov korrozii na uglerodistyh stalyah v vodno-solevyh rastvorah [The possibility of forming corrosion products on carbon steels in water-salt solutions]. In mater. 69-j nauch.-tekhn. konf. studentov, aspirantov i molodyh uchenyh UGNTU. [Materials of the 69 th scientific-technical.conf. students, graduate students and young scientists of UGNTU]. 2018. T. 1. p. 416. (In Russian).

19. Rizvanov R.G., Mulikov D.Sh., Karetnikov D.V., Cherepashkin S.E., Shirgazina R.F. Corrosion resistance of «tube - tubesheet» weld joint obtained by friction welding. Nanotehnologii v stroitel'stve $=$ Nanotechnologies in Construction. 2017, Vol. 9, no. 4, pp. 97-115. DOI: dx.doi.org/10.15828/2075-8545-2017-9-4-97-115. (In Russian).

20. Tyusenkov A.S., Rubtsov A.V., Tlyasheva R.R. Heat Resistance of Certain Structural Steels. Solid State Phenomena. 2017. Vol. 265. pp. 868-872.

\section{DeAr COlleagues!}

THE REFERENCE TO THIS PAPER HAS THE FOLLOWING CITATION FORMAT:

Latypova D.R., Latypov O.R., Bugai D.E. Influence of electrode potential on the depth of pitting corrosion in the surface structures of placed steel. Nanotehnologii v stroitel'stve $=$ Nanotechnologies in Construction. 2018, Vol. 10, no. 3, pp. 167178. DOI: dx.doi.org/10.15828/2075-8545-2018-10-3-167-178. (In Russian). 
УДК 620.193:669.715

Автор: ЛАТЫПОВА Дина Ринатовна, преп. каф. «Технология нефтяного аппаратостроения», Федеральное государственное бюджетное образовательное учреждение высшего образования «Уфимский государственный нефтяной технический университет» (ФГБОУ ВО «УГНТУ»); ул. Космонавтов, 1, г. Уфа, Российская Федерация, 450062, E-mail: d.r.latypova@mail.ru; Автор: ЛАТЫПов Олег Ренатович, д-р техн. наук, доц., проф. каф. «Технология нефтяного аппаратостроения», Федеральное государственное бюджетное образовательное учреждение высшего образования «Уфимский государственный нефтяной технический университет» (ФГБОУ ВО «УГНТУ»); ул. Космонавтов, 1, г. Уфа, Российская Федерация, 450062, E-mail: o.r.latypov@mail.ru;

Автор: БУГАЙ Дмитрий Ефимович, д-р техн. наук, проф., проф. каф. «Технология нефтяного аппаратостроения», Федеральное государственное бюджетное образовательное учреждение высшего образования «Уфимский государственный нефтяной технический университет» (ФГБОУ ВО «УГНТУ»); ул. Космонавтов, 1, г. Уфа, Российская Федерация, 450062

\section{ВЛИЯНИЕ ЭЛЕКТРОДНОГО ПОТЕНЦИАЛА НА ГЛУБИНУ ПРОНИКНОВЕНИЯ ПИТТИНГОВОЙ КОРРОЗИИ В ПОВЕРХНОСТНЫЕ СТРУКТУРЫ ПЛАКИРОВАННОЙ СТАЛИ}

АННОТАЦИЯ К СТАТЬЕ (АВТОРСКОЕ РЕЗЮмЕ, РЕФЕРАТ):

В статье приводятся результаты исследования глубины проникновения питтинговой коррозии в поверхностные структуры плакированной стали в зависимости от электродного потенциала на ее поверхности. Исследования проводили на нержавеющей поверхности образцов из стали 09Г2С/08X13, которая широко используется в строительстве металлоконструкций в нефтегазовой отрасли в условиях высокой коррозионной агрессивности технологической среды, так как она одновременно обеспечивает необходимые механические свойства и коррозионную стойкость. Показано влияние питтингообразующих компонентов коррозионной среды (ионов $\mathrm{Cl}^{-} \mathrm{u}_{2} \mathrm{O}_{3}{ }^{2-}$ ) на диффузию окислителей и развитие локальных процессов разрушений пассивной пленки. Отмечено, что максимальное влияние электродного потенциала на развитие питтинговой коррозии происходит в области вторичной пассивации. При этом глубина питтингов может достигать 180 мкм. Дальнейшее смеще- 
ние электродного потенциала поверхности способствует явлению транспассивности и приводит к появлению значительных механических напряжений в поверхностных структурах, вызывая их растрескивание. Исследование поверхностных структур позволит установить механизмы их разрушения и своевременно осуществить необходимые антикоррозионные мероприятия.

Ключевые слова: глубина питтинга, пассивная пленка, нержавеющая сталь, профиль поверхности, электродный потенциал, поляризационные кривые.

DOI: dx.doi.org/10.15828/2075-8545-2018-10-3-167-178

МАШИНОЧИТАЕМАЯ ИНФОРМАЦИЯ О CC-ЛИЦЕНЗИИ В МЕТАДАННЫХ СТАТЬИ (HTML-КОД):

$<$ a rel="license" href="http://creativecommons.org/licenses/by/4.0/"><img alt="Лицензия Creative Commons" style="borderwidth:0" src="https://i.creativecommons.org/l/by/4.0/88x31.png" $/></ \mathrm{a}><$ br $/>$ Произведение "<span xmlns:dct="http:// purl.org/dc/terms/" href="http://purl.org/dc/dcmitype/Text" property="dct:title" rel="dct:type"> Влияние электродного потенциала на глубину проникновения питтинговой коррозии в поверхностные структуры плакированной стали </span>» созданное автором по имени <a xmlns:cc="http://creativecommons.org/ns\#" href="Нанотехнологии в строительстве. -2018. - Том 10, № 3. - C. 167-178. - DOI: dx.doi.org/10.15828/2075-8545-2018-10-3-167-178" property="cc:attributionName" rel=" cc:attributionURL"> Латыпова Д.Р., Латыпов О.Р., Бугай Д.Е. </a >, публикуется на условиях <a rel="license" href="http:// creativecommons.org/licenses/by/4.0/">лицензии Creative Commons C указанием авторства 4.0 Всемирная $</ \mathrm{a}>$. $<$ br $/>0$ новано на произведении с < a xmlns:dct="http://purl.org/dc/terms/" href="http://nanobuild.ru/ru RU/nanobuild-3-2018/" rel="dct:source">http://nanobuild.ru/ru_RU/nanobuild-3-2018/</a $>$. $<$ br $/>$ Разрешения, выходящие за рамки данной лицензии, могут быть доступны на странице $<$ a xmlns:cc="http://creativecommons.org/ns\#" href="d.r.latypova@mail.ru" rel="cc:m orePermissions">d.r.latypova@mail.ru $</ a>$.

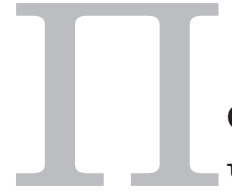

ервичная переработка нефти является основным технологическим процессом на нефтеперерабатывающих предприятиях. В связи с высокой агрессивностью поступающего на переработку углеводородного сырья оборудование первичной переработки нефти и технологические трубопроводы в большей степени подвержены коррозии [1-3]. Коррозия атмосферных и атмосферно-вакуумных колонн вызвана наличием в перерабатываемой нефти солей, неорганических кислот, сернистых соединений и хлорсодержащих органических соединений [4-5]. В процессе переработки нефти происходит гидролиз и разложение солей с хлорсодержащими органическими соединения- 
ми с выделением хлористого водорода. Его количество зависит от содержания и состава солей, остающихся в нефти после обессоливания и обезвоживания, и определяется влиянием термодеструкционных процессов на хлорсодержащие химические соединения при переработке нефти [6-8]. При этом основным источником развития локальных коррозионных процессов могут служить ионы $\mathrm{Cl}^{-}$[9-12]. Также опасность коррозионного разрушения создается при переработке сернистой нефти. В процессе крекинга освобождаются различные сернистые соединения - сульфаты, сульфиты, сульфиды, тиолы, меркаптаны. Причем основное влияние на разрушение пассивной пленки оказывают ионы тиосульфата $\mathrm{S}_{2} \mathrm{O}_{3}{ }^{2-}[13-16]$.

В качестве одного из способов защиты атмосферных колонн от разрушения используют плакирование корпуса верхней части колонны, состоящего из углеродистой стали, нержавеющей сталью [17-20]. Однако присутствие питтингообразующих элементов ионов $\mathrm{Cl}^{-} \mathrm{u}_{2} \mathrm{O}_{3}{ }^{2-}$ провоцирует пробой защитной пассивной пленки, за счет чего развивается питтинговая коррозия [6]. Оценка основных факторов развития питтингов позволит избежать дальнейшего развития коррозионных язв и ускоренного растворения корпуса колонны.

Для оценки склонности металлической поверхности к питтинговой коррозии первоначально необходимо оценить, при каких потенциалах поверхности плакированных образцов из 09Г2С/08X13 будут находиться в пассивном состоянии. Исследование пассивного состояния плакированного металла проводили с помощью потенциодинамического метода испытаний, который заключается в снятии поляризационных кривых, информирующих о скорости электрохимических реакций в данной среде. В качестве коррозионной среды использовали раствор $3 \% \mathrm{NaCl}+3 \% \mathrm{H}_{2} \mathrm{SO}_{4}$. Данный раствор представлял собой модель среды нефтепереработки, в которой преобладали ионы $\mathrm{Cl}^{-}, \mathrm{SO}_{4}{ }^{2-}$ и $\mathrm{S}_{2} \mathrm{O}_{3}{ }^{2-}$. Поляризационные кривые были получены с помощью потенциостата серии «IPC-Pro M» со скоростью развертки потенциала 3 мB/с в прижимной трехэлектродной электрохимической ячейке. В качестве электрода сравнения использовали хлорсеребряный электрод. Вспомогательным электродом служил платиновый электрод. Поляризационные кривые снимали на нержавеющей поверхности плакированного образца из 09Г2C/08X13. На рис. 1 показаны катодная и анодная поляризационные кривые для плакированного образца. 


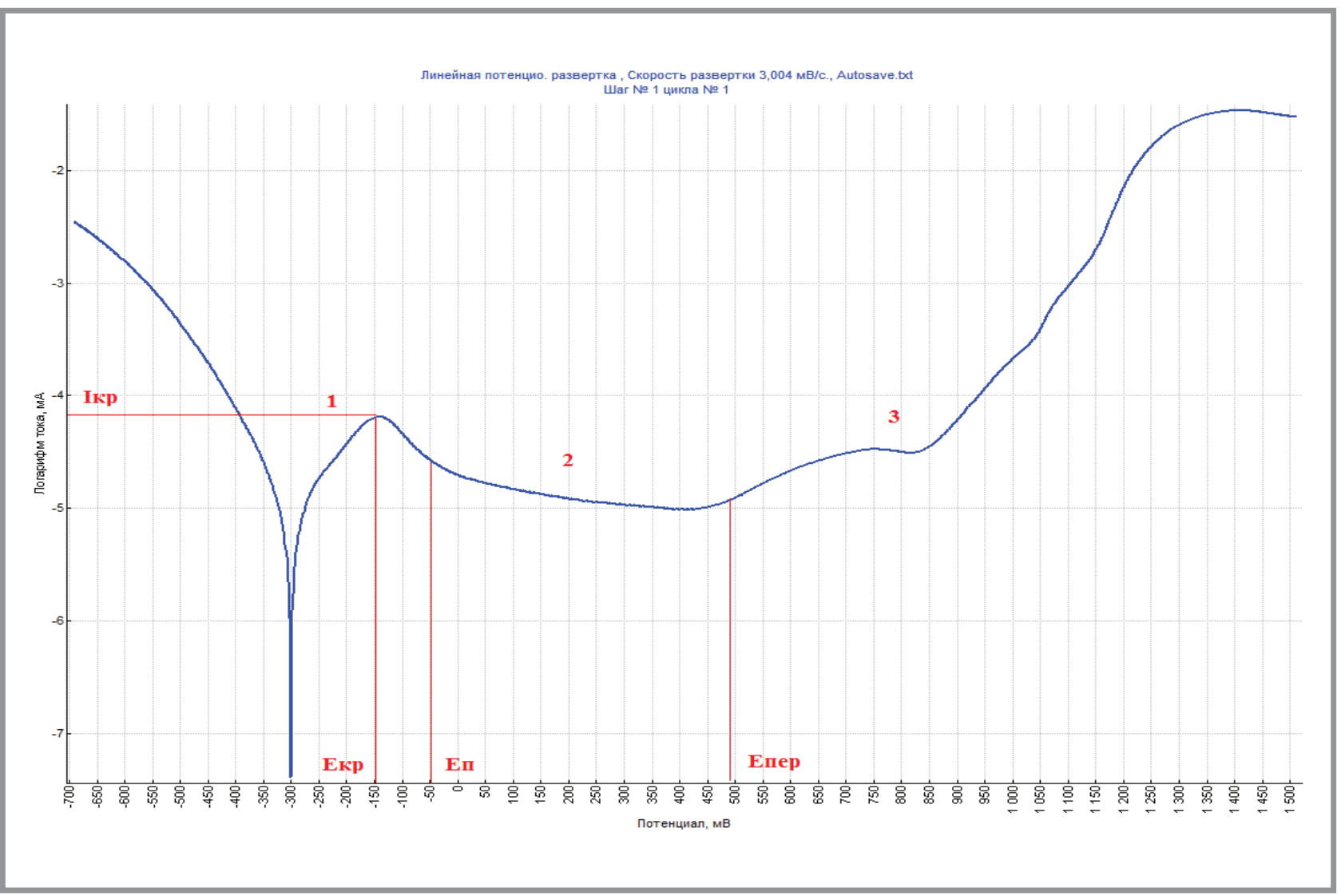

Puc. 1. Поляризационные кривые на нержавеющей поверхности плакированного образца 09Г2С/08X13

Согласно рис. 1 на анодной кривой можно отметить:

- область начала пассивации (1) в интервале от критического потенциала $E_{\text {кр }}$ до потенциала начала пассивного состояния $E_{\text {п }}$;

- устойчивое пассивное состояние (2) ограниченного потенциалом начала пассивного состояния $E_{\text {п }}$ и потенциалом перепассивации $E_{\text {пер}}$;

- область вторичной пассивации (пологий ход кривой) (3) и участок транспассивности после потенциала перепассивации $E_{\text {пер}}$.

Дальнейшие исследования были направлены на изучение питтинговой коррозии в условиях пробоя пассивной пленки в отмеченных областях электродных потенциалов. С помощью потенциостата поддерживали определенные значения электродных потенциалов нержавеющей поверхности плакированного образца 09Г2С/08X13 в течение 30 минут. При этом наблюдали появление питтингов на поверхности. Для наблюдения питтинговой коррозии использовали металлографиче- 


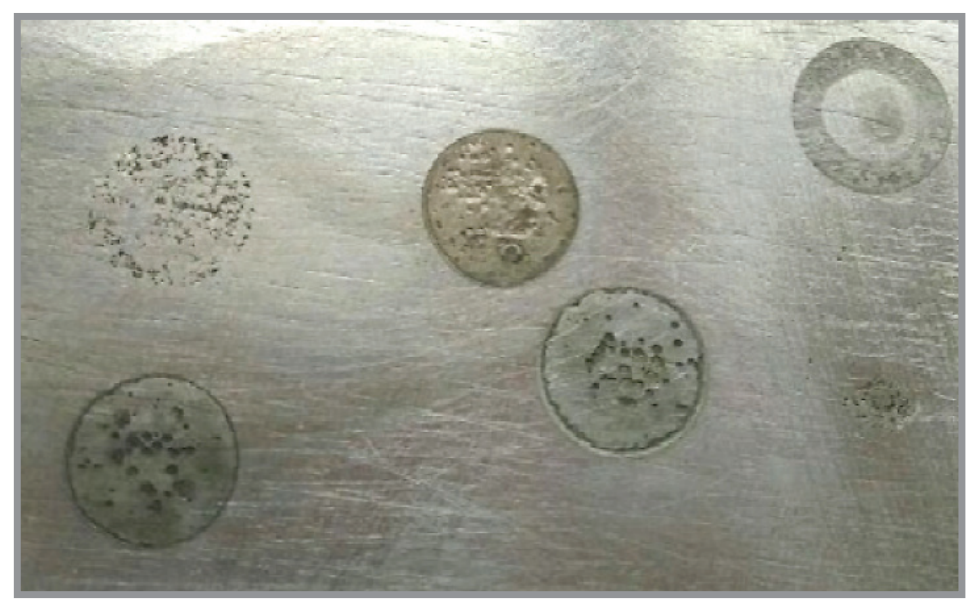

Puc. 2. Участки питтинговой коррозии на нержавеющей поверхности плакированного образца 09Г2С/08X13 при различных значениях электродного потенциала (х100)

ский микроскоп «Метам-22M» с увеличением в 100 раз. На рис. 2 показана поверхность образца после проведения испытаний.

Стоит отметить, что в области устойчивого пассивного состояния питтинги образовывались довольно редко и имели небольшую глубину.

После испытания в течение получаса образцы извлекали из коррозионной среды и измеряли глубину появившихся питтингов и язв с помощью ультразвукового профилометра «Surtronic S-100». На рис. 3 показаны результаты измерений глубины проникновения питтинга на нержавеющей поверхности плакированного образца 09Г2С/08X13 при различных значениях электродного потенциала.

Из рис. 3 следует, что наибольшая глубина питтингов достигается при значениях электродных потенциалов, находящихся в областях (1) и (3). Причем в области вторичной пассивации происходят максимальные пробои пассивной пленки до 180 мкм. Как и следовало ожидать, профилограмма нержавеющей поверхности плакированного образца практически повторяет ход анодной поляризационной кривой. В области устойчивого пассивного состояния глубина питтингов была несущественной, в пределах 20 мкм, т.е. в пределах шероховатости поверхности образца.

Таким образом, проведенные исследования показали, что изменение электродного потенциала нержавеющей поверхности плакированного слоя влияет на разрушение пассивной пленки и приводит к развитию питтинговой коррозии. Наличие коррозионных компонентов 


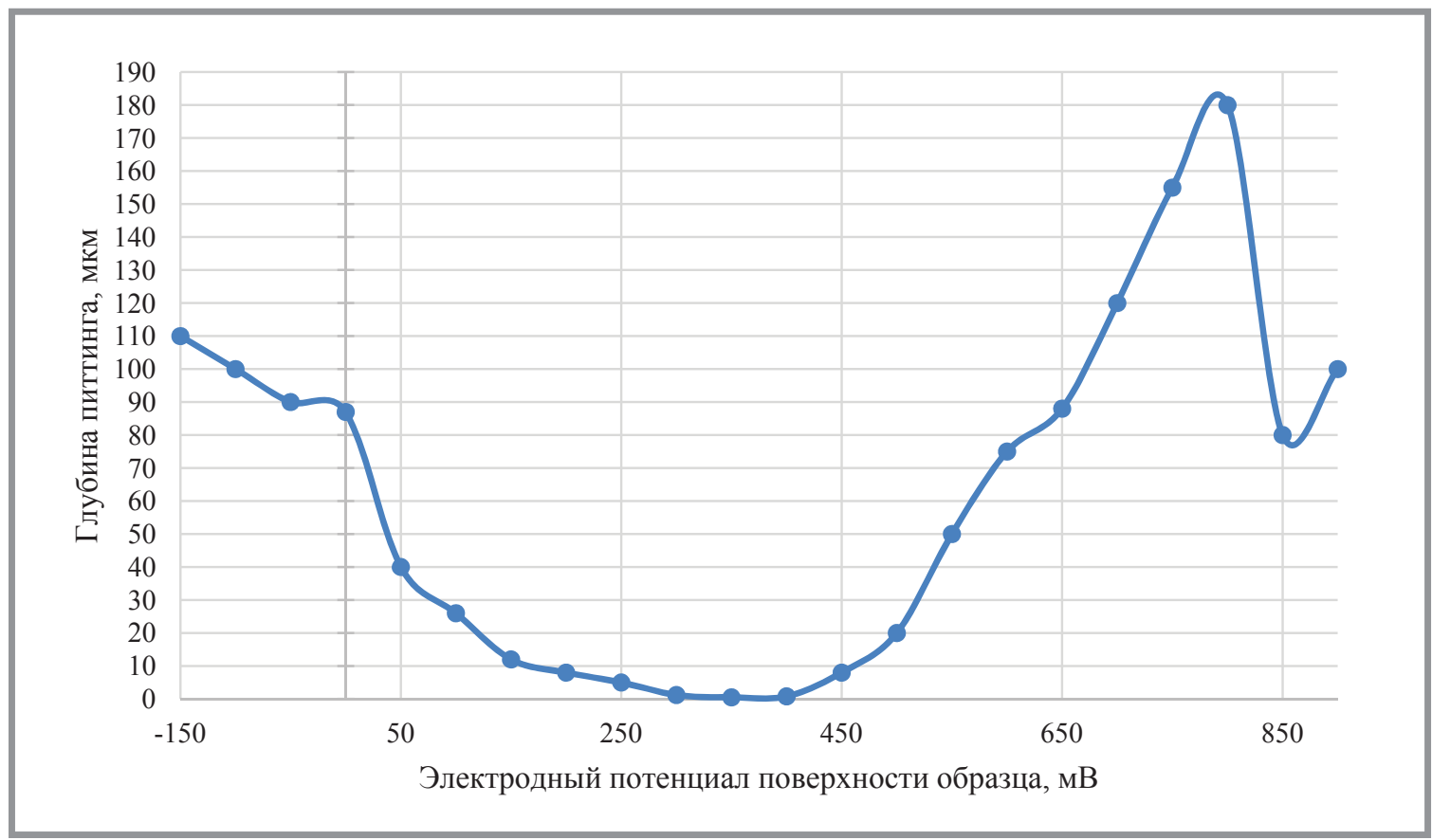

Рис. 3. Результаты измерений глубины проникновения питтинга на нержавеющей поверхности плакированного образца 09Г2С/08X13 при различных значениях электродного потенциала

ионов $\mathrm{Cl}^{-}, \mathrm{SO}_{4}{ }^{2-}$ и $\mathrm{S}_{2} \mathrm{O}_{3}{ }^{2-}$ провоцирует локальные пробои пассивной пленки и способствует появлению первоначальных коррозионных язв на наноуровне. Однако в дальнейшем протекание электрохимических реакций на поверхности нержавеющей стали способствует ее растворению до видимых размеров, что показывает необратимость процесса коррозии и дальнейшего разрушения металлоконструкции. Своевременный анализ очагов питтинговой коррозии и правильный способ защиты от коррозии позволит предотвратить отказ нефтеперерабатывающего оборудования и обеспечить его надежную и безопасную работу в течение всего эксплуатационного периода.

\section{Библиографический список:}

1. Алиыбеева А.И., Бурлов В.В., Кузинова Т.М., Соколов В.Л., Решетников С.М. Питтинговая коррозия сталей в условиях первичной переработки нефти // Коррозия: материалы, защита. - 2009. - № 3. - С. 6-10. 
2. Дайрова К.Н., Латыпов О.Р., Бугай Д.Е. Коррозия колонны гидроочистки дизельного топлива // Матер. 67-й науч.-техн. конф. студентов, аспирантов и молодых ученых УГНТУ. - Уфа: Издательство УГНТУ, 2016. - Кн. 1. - С. 217-218.

3. Латыпова Д.Р. Контактная коррозия плакированного слоя атмосферной колонны // Сборник матер. II Внутривуз. науч.-практ. конф.: «Современные технологии в образовании и промышленности: от теории к практике». - Уфа: Изд-во «Нефтегазовое дело», 2018. - С. 165-167.

4. Калилуллина Э.Р., Латыпова Д.Р., Бугай Д.Е. Защита холодильного оборудования от локальной коррозии // Матер. 69-й науч.-техн. конф. студентов, аспирантов и молодых ученых УГНТУ. В 2 т. - Уфа: Изд-во УГНТУ, 2018. - Т.1. - С. 395.

5. Боев Е.В., Афанасенко В.Г., Латыпов О.Р., Черепашкин С.Е., Боева Н.И. Повышение качества водотопливных эмульсий // Уральский научный вестник. - 2018. T. 2, № 4. - С. 19-22.

6. Муканова С.С., Латыпова Д.Р., Бугай Д.Е. Влияние температуры на скорость питтинговой коррозии нефтеперерабатывающего оборудования, выполненного из нержавеющих сталей // Матер. 69-й науч.-техн. конф. студентов, аспирантов и молодых ученых УГНТУ. В 2 т. - Уфа: Изд-во УГНТУ, 2018. - Т. 1. - С. 409.

7. Latypov O.R. Reduction of Salt Deposits on the Surface of Oilfield Equipment by Management of Electrochemical Parameters of the Medium / Chemical and Petroleum Engineering. November 2015, Vol. 51, Issue 7. pp. 522-525. DOI: dx.doi.org/10.1007/ s10556-015-0079-z.

8. Щербаков А.И., Касаткина И.В., Паличева А.С., Залавутдинов Р.Х., Дорофеева B.H. Питтинговая коррозия дуплексной стали 08X21H6M2T в нейтральной хлоридной среде при производстве калийных удобрений // Коррозия: материалы, защита. - 2017. - № 9. - С. 31-36.

9. Овчинникова В.В., Латыпова Д.Р., Латыпов О.Р., Бугай Д.Е. Щелевая коррозия нефтезаводского оборудования в условиях действия ионов хлора // Матер. 68-й науч.-техн. конф. студентов, аспирантов и молодых ученых УГНТУ. - Уфа: Издательство УГНТУ, 2017. - Кн. 1. - С. 365.

10. Овчинникова В.В., Латыпов О.Р., Бугай Д.Е. Защита нефтезаводского оборудования от щелевой коррозии в условиях действия ионов хлора // Матер. Всеросс. науч.-практ. конф. с междунар. участием: «Инновационные технологии в промышленности: образование, наука и производство». - Уфа: Изд-во «Нефтегазовое дело», 2016. - С. 408-409.

11. Latypov O.R., Bugai D.E., Boev E.V. Method of Controlling Electrochemical Parameters of Oil Industry Processing Liquids // Chemical and Petroleum Engineering. July 2015, Vol. 51, Issue 3. pp. 283-285. DOI: dx.doi.org/10.1007/s10556-015-0038-8.

12. Латыпов О.Р., Бугай Д.Е., Рябухина В.Н. Защита нефтегазового оборудования от коррозии методом поляризации // Проблемы сбора, подготовки и транспорта нефти и нефтепродуктов. - 2015. - № 3 (101). - С. 155-164.

13. Латыпова Д.Р., Мальиев В.А., Латыпов О.Р., Лаптев А.Б., Бугай Д.Е. Оценка комплексной ингибиторной защиты от коррозии водооборотных систем установок гидрокрекинга // матер. Междунар. науч.-практ. конф.: «Нефтегазопереработка 2017». - Уфа: Издательство ГУП ИНХП РБ, 2017. - С. 208-209. 
14. Скуридин Н.Н., Латыпова Д.Р., Печенкина М.Ю., Латыпов О.Р., Бугай Д.Е., Рябухина B.H. Формирование противокоррозионных пленок на металле нефтепромыслового оборудования методом поляризации технологических жидкостей // Нефтяное хозяйство. - 2018. - № 5. - С. 84-86. - DOI: 10.24887/0028-2448-2018-5-84-86.

15. Миракян C.М., Латыпов О.Р., Бугай Д.Е., Раскильдина Г.З. Поляризационные исследования ингибирующей эффективности некоторых вторичных аминов // Башкирский химический журнал. - 2017. - Т. 24, № 2. - С. 42-45.

16. Каэтану Ж.Б., Латыпова Д.Р., Латыпов О.Р. Исследование коррозии металла обсадных труб // Сборник матер. II Внутривуз. науч.-практ. конф.: «Современные технологии в образовании и промышленности: от теории к практике». - Уфа: Издво «Нефтегазовое дело», 2018. - С. 169-171.

17. Tyusenkov A.S. Chemical resistance of steel $13 \mathrm{CrV}$ (rus 13XФA). // Journal of Chemical Technology and Metallurgy. Vol. 52., Iss. 4. - 2017. - pp. 766-772.

18. Овчинникова В.В., Печенкина М.Ю., Латыпов О.Р. Возможность формирования продуктов коррозии на углеродистых сталях в водно-солевых растворах // Матер. 69-й науч.-техн. конф. студентов, аспирантов и молодых ученых УГНТУ. В 2 т. Уфа: Изд-во УГНТУ, 2018. - Т. 1. - С. 416.

19. Rizvanov R.G., Mulikov D.Sh., Karetnikov D.V., Cherepashkin S.E., Shirgazina R.F. Corrosion resistance of «tube - tubesheet» weld joint obtained by friction welding // Nanotehnologii v stroitel'stve $=$ Nanotechnologies in Construction. 2017, Vol. 9, no. 4, pp. 97-115. DOI: dx.doi.org/10.15828/2075-8545-2017-9-4-97-115. (In Russian).

20. Tyusenkov A.S., Rubtsov A.V., Tlyasheva R.R. Heat Resistance of Certain Structural Steels. Solid State Phenomena. 2017. Vol. 265, pp. 868-872.

\section{УВАЖАЕМЫЕ КОЛЛЕГИ! \\ ПРИ ИСПОЛЬЗОВАНИИ МАТЕРИАЛА ДАННОЙ СТАТЬИ \\ ПРОСИМ ДЕЛАТЬ БИБЛИОГРАФИЧЕСКУЮ ССЫЛКУ НА НЕЁ:}

Латыпова Д.Р., Латыпов О.Р., Бугай Д.Е. Влияние электродного потенциала на глубину проникновения питтинговой коррозии в поверхностные структуры плакированной стали // Нанотехнологии в строительстве. - 2018. - Том 10, № 3. - C. 167-178. - DOI: dx.doi.org/10.15828/2075-8545-2018-10-3-167-178.

\section{Dear Colleagues!}

THE REFERENCE TO THIS PAPER HAS THE FOLLOWING CITATION FORMAT:

Latypova D.R., Latypov O.R., Bugai D.E. Influence of electrode potential on the depth of pitting corrosion in the surface structures of placed steel. Nanotehnologii v stroitel'stve $=$ Nanotechnologies in Construction. 2018, Vol. 10, no. 3, pp. 167178. DOI: dx.doi.org/10.15828/2075-8545-2018-10-3-167-178. (In Russian). 